Europe". The very form of this statement shows how far many wellintentioned people have fallen into the trap prepared for them by Dr. Goebbels. The concept of a Christian Western Europe containing all the virtues as a bulwark against the evils of bolshevism was on of his favourite ways of justifying Nazi Germany and is being echoed even to-day by his tolerated disciple General Franco. To fall for this 'holier than thou' attitude is a particular weakness of Anglo-American culture : it is apt to appear to other countries as nauseating hypocrisy Men of science in Great Britain should be more wary of accepting this flattering ascription to themselves of the monopoly of moral values. Quite apart from the fact that the Soviet Union has as good a claim as a Christian country and as heir to the same classical culture a ourselves, the cultures of Islam. India and China have contributed their share to the common heritage. "Respect for human personality, freedom of worship, freedom of investigation" ar human personality, exclusive mark of christian ethics. exclusive mark of Christian ethics: they are concessions won from Christian churches in a long struggle in which science played a notable part. Communism has never denied these principles; in fact the those who openly rejected them. those who openly rejected them. In so far as we admit and propagate this concept of a radical moral division of th

That may ultimately lead to war. The opportunity for new international unity which we all earnestly desire is to be found rather in the discovery of common ground between ourselves and the Soviet Union than in pointing out superficial, Council of Scientiflc Unions do effectively speak for seience, and the Soviet Union is represented on many of these councils. The same appeal for understanding and unity has in recent days been made by than citizens, should know that it is in this direction that our con tribution to world welfare can be made.

Birkbeck College,

J. D. BRRNAT

London, F.C.4.

Oct. 7 .

1 "The Atom and the Charter", published jointly by the Fabian Society and the Association of Seientific Workers (Sept. 1946).

\section{Infra-Red Recording with the Cathode Ray Oscilloscope}

IN Nature of August 10, p. 196, King, Temple and Thompson have described under the above title an infra-red spectrometer in which the spectrum is displayed on a cathode ray oscilloscope. This spectrometer is virtually identical with the one which we described in Nature earlier this year (April 27, p. 547), except that the trace is smoothed after rectiflcation. The impression conveyed by their communication is that theirs was a parallel piece of work, which was concluded shortIy after ours and was done quite independently. No mention is made of the fact that our spectrometer was demonstrated to Dr. Thompson on February 28, when full details were given of our procedure, and that it was only after this information had been given that work was started at Oxford on this project. Furthermore, the modification mentioned, and claimed as an advance, was introfuced by us some

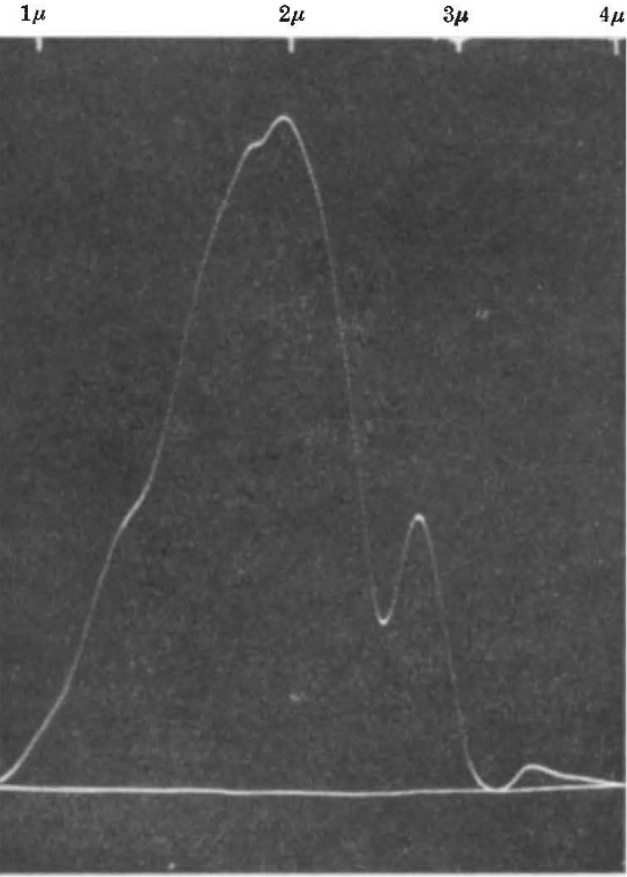

INFRA-RED EMTSSION SPEOTRUM FROM A NERNST FILAMENT BETWEEN $1 \mu$ AND $4 \mu$ SHOWING SUPERIMPOSED MENT BETWEEN $\mu$ RPTION BANDS AT $1 \cdot 4 \mu, 1 \cdot 9 \mu, 2 \cdot 8 \mu$ (DUE TO $\mathrm{H}_{2} \mathrm{O}$ AND CO FIIM OF HYDROOARBON MATERIAL) three months ago, and Dr. Thompson was informed of this several weeks before the date of his communication to Nature.

Once an advance of the kind we described has been made, it is obvious that many modifications and improvements can be made in the method of presentation. The accompanying photograph shows that the modifications which we have introduced since the date of our original communication make our apparatus considerably superior to the Oxford one in suppression of noise, indication of base line and detection of weak absorption bands. Our spectrum is strictly comparable with that shown in Fig. 2 of the communication from the Oxford workers.

Cavendish Laboratory and Cambridge.

M.Y colleagues and I are not conscious of any act of impropriety in this matter, but the comments above give a misrepresentation of the position, to which I must reply briefly. It was shown more than two years ago by the work of Baker and Robb that a cathode ray tube could be used to record an infra-red spectrum, and the spectroscopic panel of the Hydrocarbon Research Group of the Institute of Petroleum decided to explore the problem as one of its several projects. By mutual agreement between Dr. Sutherland and myself, this particular project was begun by him at Cambridge, since at that time duplication of the necessary apparatus would have been difficult, if not impossible. In company with others, several of my colleagues and I saw the instrument of Daly and Sutherland in operation on February 28, but re. ceived no information about its construction other than that contained in their communication in Nature, to which acknowledgment was made in our own communication. At that time, my colleagues raised with the Cambridge workers the possibility of using a smoothed trace, since we were hoping to use this method when the necessary bolometer could be obtained; but we were given to understand that Daly and Sutherland preferred their own form of record. After obtaining a Bell Telephone thermistor in May last, we were able to complete our instrument and to demonstrate it to many visitors during June. I was eventually informed indirectly, and later directly by Dr. Sutherland, that he had now gone over to the form of recording which we had used. At no time yet have my colleagues and I ever seen any of the technical drawings or circuits used by the Cambridge workers, or had any details of the experimental arrangements not mentioned in their published note. So far as we can tell, our form of chopped wave, the amplifiers, and other electrical equipment, differ in some important features from those used by them, and the whole instrument differs from theirs much as two different types of spectrometer differ. As stated in our note, we also have already made, or are in photographs shown in our note were taken.

Physical Chemistry Department,

H. W. THOMPSON Oxford.

WE note that Dr. Thompson and his colleagues do not consider there is anything improper in failing to acknowledge information given to them considerably before the date of publication.

Dr. Thompson's statement that no information (other than that contained in our original communication) was obtained by seeing our apparatus in action, and incidentally having every question answered on that occasion, is not justiflable. To take only one instance: the method of scanning by means of a carefully designed cam, coupled by method of scanning by means of a carefully designed cam, coupled by potentiometer to the $X$ plates of the cathode ray tube, and described by the seen by them and explained to them and others present on that occasion. In this connexion, moreover, the

r. Thompson's note makes puzzling reading. The implication in Dr. Thompson's note that we followed the Oxford group in introducing smoothing is also incorrect. We have never been informed what the Oxford workers were doing, and on two occasions when we visited Oxford, while their apparatus was under construction, we were not invited to see it. It is certainly true that we gave them no circuit diagrams, and this may well account for their obvious lack of suecess in eliminating 'noise' from their spectra.
Dr. Thompson refers to the work of Baker and Robb. This was indeed the first attempt to present an infra-red spectrum on a cathode ray screen, and we gladly acknowledge the stimulus which their work provided to us in this direction. However, the Baker and Robb apparatus was never completed, as they themselves state in their paper. Our attack on the problem differed fundamentally from that of $\mathrm{Baker}$ and $\mathrm{Robb}$, and for the first time gave a simple practicable instrument which could be easily duplicated by anyone interested.

The statement that "the spectroscopic panel of the Hydrocarbon Research Group of the Institute of Petroleum decided to explore the problem .; and by mutual agreement this project was begun at were asked to submit independently to the Panel our proposals for future research. The problem of cathode ray presentation never appeared in Dr. Thompson's programme at any time, so there was no question of allocating it to Cambridge in any division of work the really essential piece of this apparatus, namely, the thermistor bolometer, would have been just as accessible to Dr. Thompson as it was to us.

So far as we are concerned, we do not wish your columns to be burdened by any further communications on this affair.

\section{G. B. B. M. SUTHERLAND}

Mr colleagues and I feel that to deal with points made by Daly and Sutherland would only lead to fruitless correspondence ; therefore, while repudiating the new charges brought against us, we will refrain from further comment.

H. W. THOMPSON 